\title{
Case Study on Developing an Elderly Automatic Shower System
}

\author{
Jonghyun Kim, Jaesoo Hong, Keyoungjin Chun \\ Gerontechnology Center, Korea Institute of Industrial Technology, Cheonan, 331-825
}

\begin{abstract}
Objective: The aim of this study is developing an elderly automatic showering system by optimizing nozzle position and angle of water injection on ergonomics approach. Background: The elderly living in nursing home or hospital were increased by an aging population. Helping the elderly on showering is so hard. In addition, the existing showering/bathing systems are not effective because shower pattern of the elderly and washed range of nozzle were not considered. Method: Firstly, basic specification were determined by anthropometric approach. Secondly, position of nozzle and angle of water injection were determined through observation of elderly behavior on showering. And, finally, they were optimized by washing test and showering simulation. Results: On showering importance of body parts were able to analysis through observation of elderly behavior. The position of nozzle and angle of water injection was able to optimize by showering simulation. The automatic showering system was developed by considering their results. Conclusion: The most important technology of developing a showering system is the determining position of nozzle and angle of water injection, number of nozzle. It was developed by applying its results through user centered-research. Application: The user centered-research of developing products was able to apply directly to develop automatic bath, showering products etc. Further more it was available to apply senior friendly products.
\end{abstract}

Keywords: Shower Nozzle position, Observation of Shower motion, Senior friendly product design, Ergonomics design

\section{Introduction}

급격한 고령화로 인하여 노인요양시설 및 노인전문병원에 서 생활하는 고령자의 수가 증가하고 있는 추세이다. 이와 같은 노인요양시설이나 노인전문병원에서 몸이 불편한 고령 자를 씻기는 행위인 샤워수발은 수발자에게는 매우 힘든 노 동이 되고 있다. 이러한 수발자의 불편함을 해소하고자 일본 을 비롯한 유럽 등에는 고령자의 샤워 및 목욕수발을 위한 여러 가지 종류의 자동샤워 및 목욕장치가 개발되어 있는 실정이다.

또한 고령자의 삶의 질 향상 측면에서도 목욕이나 샤워는 중요한 역할을 한다. 스스로 샤워 - 목욕이 가능한 고령자는
샤워를 통해 자신감을 얻을 수 있고, 샤워를 통한 스트레스 해소 및 기분전환 효과, 청결유지에 관한 기본적인 일상생 활이 가능해짐에 따라 샤워 - 목욕은 단순한 씻는 행위를 벗 어나 고령자에게는 중요한 일상생활 중에 하나이다.

2006년 기준, 고령자 및 장애인을 위한 입욕기기 국내시 장은 매출이 95억원에 달하고 있으며, 국내 입욕기기 관련 업체의 상품개발이나 생산이 미흡한 상황으로 대부분의 입 욕기기는 일본에서 수입되고 있는 상황이다(Chun et al., 2009). 이처럼 일본에서 수입되는 기존 제품들은 노즐의 위 치에 대한 연구가 부족하여 효과적인 샤워가 어렵고, 좌식형 자동샤워시스템은 아직 개발된 사례가 없다.

국내에서 생산되는 입욕기기의 종류는 미끄럼 방지 장치, 목욕의자, 지지핸들 및 지지봉(안전바) 등의 단순한 보조기

Corresponding Author: Keyoungin Chun. Gerontechnology Center, Korea Institute of Industrial Technology, Cheonan, 331-825.

Mobile: 010-3171-6345, E-mail: chun@kitech.re.kr

Copyright@2011 by Ergonomics Society of Korea(pISSN:1229-1684 eISSN:2093-8462). All right reserved. 
기들이 대부분이다. 입욕기기와 관련된 국내연구개발 사례 를 살펴보면, 차량에 설치된 이동형 목욕시스템이 개발된 사 례가 있으나, 실내에서 사용되는 자동샤워 또는 목욕장치의 개발은 전무한 실정이다.

또한 국내요양시설에서 기존 제품(일본)을 사용할 때 있 어 노즐위치가 적절하게 위치되지 않아 사용자의 몸에 많은 부분이 물이 닿지 않고, 이는 수발자의 수발범위가 넓어져 비효율적인 샤워수발동작을 유도하는 문제점으로 나타났다. 이에 본 연구에서는 고령자용 자동샤워시스템을 개발하는데 있어 샤워노즐의 위치 및 분사각도의 최적화 연구를 중심으 로 연구를 진행하였다.

본 연구의 목적은 고령자용 자동샤워시스템의 인간공학적 제품설계와 사용자 중심 디자인을 통한 자동샤워시스템 개 발에 그 목적을 두고 있다.

본 연구에서는 첫 번째로, 기존 자동샤워시스템들의 분석 을 통한 사용자 요구사항을 도출하였다. 두 번째로, 고령자 인체치수 적용을 통한 자동샤워시스템의 샤워의자 설계 가 이드라인을 제시하였다. 세 번째로, 고령자들의 샤워 시 행 동특성 분석을 통한 고령자들의 씻는 부위별 중요도를 평 가하였다. 이를 통한 샤워노즐의 위치 및 분사각을 분석하 였다. 네 번째로, 세정실험과 노즐위치 시뮬레이션을 통하여 노즐위치를 최적화하였다. 마지막으로 앞서 제시한 고령자의 인체치수 적용 설계 가이드 및 최적 노즐위치 및 분사각 설정에 따른 자동샤워시스템의 디자인 및 구조설계를 수행 하였다.

\section{Analysis of Existing Products}

자동샤워/목욕시스템은 아직 국내에서 개발된 사례가 없으 며, 일본제품이 주를 이루고 있다. 그러나 일본제품은 매우 고가이다. 그리고 일본인들은 분무형태의 약한 수압의 샤워 를 즐기는 반면, 한국인들은 강한 수압으로 물줄기를 몸에 분사하는 것을 선호한다. 또한 체계적인 사용자 중심적 연구 에 의한 제품개발이 미흡하다(Chun et al., 2007). 이러한 일본제품들의 단점은 한국 사용자 특성에 맞고, 사용자 중심 적인 자동샤워시스템의 개발 필요성을 제기한다. 따라서, 기 존 일본제품들의 단점을 보완하고, 기술적 특성을 조사하기 위하여 제품의 가격 및 사용형태에 대하여 분석하였고, 이를 토대로 자동샤워시스템의 개발 방향을 설정하였다.

기존의 일본의 자동샤워/목욕시스템들은 크게 좌식형과 와 상형으로 나누어진다. 그리고 샤워와 목욕의 비중을 볼 때, 수욕을 즐기는 일본의 목욕문화에서는 욕조형태의 제품이 대부분이다. 또한 대부분의 제품이 와상형 제품이고, 좌식형
으로 된 샤워제품은 아직 개발된 사례가 없다(Table 1). 또 한 기존의 제품들은 체계적인 노즐위치 연구가 생략되어 있 어 수발자들의 비효율적인 수발동작을 유발하는 문제점이 지적되어 왔다(Chun et al., 2009).

Table 1. Analysis of characteristics on existing products

\begin{tabular}{|c|c|c|}
\hline Image & Type & Functional features \\
\hline & $\begin{array}{l}\text { Bathtub of } \\
\text { Bed Type }\end{array}$ & $\begin{array}{c}\text { Automatically Transfer } \\
\text { between Bathtub and } \\
\text { Shower trolley }\end{array}$ \\
\hline & $\begin{array}{l}\text { Bathtub of } \\
\text { Bed Type }\end{array}$ & $\begin{array}{l}\text { Water Bathing through } \\
\text { a Retractable door }\end{array}$ \\
\hline & $\begin{array}{l}\text { Bathtub of } \\
\text { Bed Type }\end{array}$ & $\begin{array}{c}\text { Water Bathing } \\
\text { through Lifting Bathtub }\end{array}$ \\
\hline & $\begin{array}{l}\text { Bathtub of } \\
\text { Bed Type }\end{array}$ & $\begin{array}{l}\text { Water Bathing } \\
\text { through Swivel } \\
\text { Lifting Chair }\end{array}$ \\
\hline & $\begin{array}{l}\text { Bathtub of } \\
\text { Chair Type }\end{array}$ & $\begin{array}{c}\text { Water Bathing } \\
\text { Using the Carrier Chair }\end{array}$ \\
\hline & $\begin{array}{l}\text { Bathtub of } \\
\text { Chair Type }\end{array}$ & $\begin{array}{c}\text { Water Bathing } \\
\text { Using the Carrier Chair }\end{array}$ \\
\hline & $\begin{array}{l}\text { Bathtub for } \\
\text { Lower-body }\end{array}$ & $\begin{array}{l}\text { Water Bathing of } \\
\text { Lower-body }\end{array}$ \\
\hline$\frac{\operatorname{sig}}{\pi}$ & $\begin{array}{l}\text { Showering } \\
\text { System of } \\
\text { Bed Type }\end{array}$ & $\begin{array}{l}\text { Dome Showering } \\
\text { of Bed Type }\end{array}$ \\
\hline
\end{tabular}

현재 국내에서 일본제품을 사용하고 있는 시설(노인전문 요양시설: 효원, 구립 영등포케어센터)의 목욕수발자들을 대 상으로 의견을 수렴해본 결과 다음과 같다. (1) 일본의 자동 샤워장치는 물줄기의 세기가 약해 고령자들의 만족감이 떨 어진다. (2) 목욕장치(욕조형태) 가 대부분이어서 여러 사람이 사용하기에는 위생 상의 문제점이 있다. (3) 물을 채우는 시 간으로 인해 전체적으로 씻는 시간이 오래 걸린다. (4) 낭비 
되는 물의 양이 많다. 따라서, 본 연구에서는 샤워수발자들의 의견을 반영하여 국내의 노인병원, 요양원 등을 대상으로 여 러 고령자들이 적은 시간에도 위생적으로 사용할 수 있는 좌 식형의 자동샤워시스템으로 제품의 개발 방향을 설정하였다.

\section{Guideline of Showering Chair Design}

자동샤워시스템의 치수를 정하는 데 있어서 가장 중요한 설계치수들 중에 하나가 의자/좌면 부위의 설계치수들이다. 또한 제품외형의 치수를 정하는 데에 있어서도 의자의 설계 치수들은 중요하게 결정되어야 할 요소들이다.

따라서 의자부위는 인체치수 적용원리에 따라 65세부터 90 세까지의 고령자 인체치수를 통한 설계치수를 도출하여 적용하였다(Size Korea, 2008).

\subsection{Design dimensions of showering chair(Figure 1)}

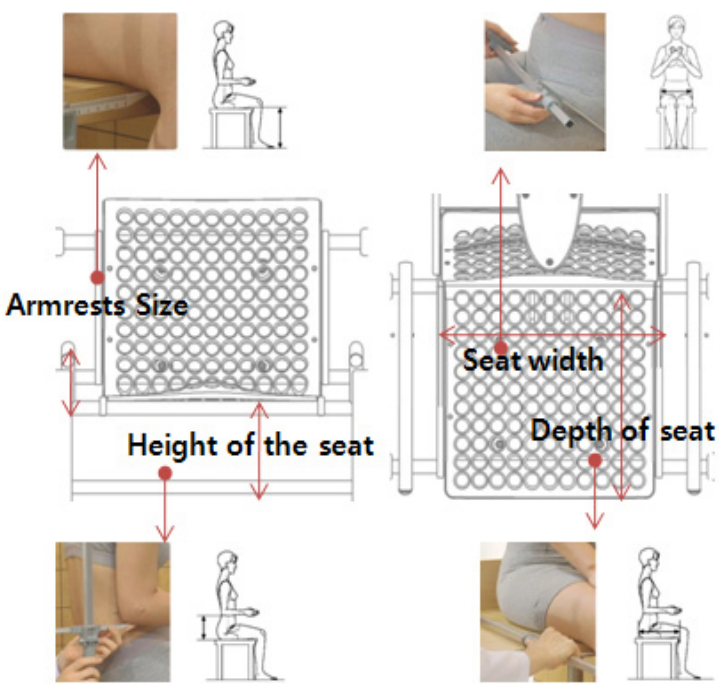

Figure 1. Design dimension

\subsubsection{Seat width}

엉덩이가 넓은 사람이나 좁은 사람이나 엉덩이 크기에 상 관없이 모든 사람이 앉을 수 있으려면 엉덩이가 큰 사람을 기준으로 만들어져야 할 것이다. 따라서 '앉은 엉덩이 너비' 라는 인체치수를 활용하였으며, 엉덩이 너비는 여자가 남자 보다 더 크므로, 최대치인 여성 $95 \%$ tile을 적용하였다.

\subsubsection{Height of the seat}

'앉은 오금높이'를 적용하였는데 의자높이의 경우 낮은 경
우에는 키가 작은 사람이나 큰 사람 모두 앉을 수 있지만 의자 높이가 높은 경우에는 키가 작은 사람은 앉기에 불편하 므로 의자 높이는 여성 $5 \%$ tile인 최소치를 적용한다.

\subsubsection{Depth of seat}

'앉은 엉덩이 오금 수평 길이'라는 인체치수를 적용하는 데 의자 깊이 역시 최소치 설계를 이용한다. 이는 치수가 큰 사람을 기준으로 할 때에 치수가 작은 사람들은 등받이 등을 받칠 수 없지만 치수가 큰 사람들은 의자의 깊이 작아도 크게 불편함이 없으므로 의자의 깊이는 여자의 $5 \%$ tile을 적 용한 최소치 설계로 한다.

\subsubsection{Armrests size}

팔걸이에 관한 인체치수 적용은 극단치 설계의 적용이 애 매하다. 너무 높으면 낮은 사람이 불편하고 너무 낮은 경우 팔걸이로서 의미가 없어지므로 평균치 설계를 적용한 전체 의 $50 \%$ tile을 적용한 인체치수로 설계한다. 팔걸이의 길이 역시 평균치 설계를 적용한다. 또한, 팔걸이와 팔걸이 사이 의 너비는 의자 너비에 맞추어 설계하거나 약간 크게 설계 한다. 이처럼 인체치수를 적용할 때에는 인체치수를 적용할 각각의 설계요소에 어떤 인체치수를 적용할지, 극단치와 평 균치 중에 어느 것을 선택할지 결정하여 적용하였다.

\subsection{Guideline of showering chair design dimensions}

자동샤워의자의 설계치수는 크게 의자좌석과 팔걸이 부분 으로 나누어져 의자의 높이, 너비, 깊이, 팔걸이의 높이, 너 비, 사이 길이로 나뉘어 아래(Table 2) 와 같이 정리하였다.

\section{Observation of the Elderly Behavior in the Showering}

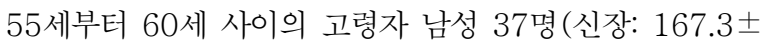
$5 \mathrm{~cm}, 59.9$ 세 $\pm 4.3 \mathrm{~cm}, 68.7 \pm 6.1 \mathrm{~cm} \mathrm{~kg}$ ) 을 대상으로 샤워 시 행동에 대한 관찰을 실시하였다. 촬영장비로는 피실험자 의 행동특성을 측정하기 위해 여러 방향에서 동시촬영이 가 능한 CCTV 카메라 4대, CCTV 카메라 컨트롤용 DVR 1대, 화면 출력 및 녹화용 노트북, 휴대용 캡쳐카드와 디지털 캠 코더를 사용하였다(Figure 2).

행동관찰을 통하여 샤워 시 고령자의 행동특성을 분석하 였고, 분석결과를 기준으로 하여 자동샤워시스템의 노즐위치 및 분사각을 설정하였다(Chun et al., 2007). 
Table 2. Guideline of design dimensions on Auto shower chair

\begin{tabular}{|c|c|c|c|c|c|}
\hline $\begin{array}{l}\text { Shower } \\
\text { chair }\end{array}$ & Components & Reference & Industrial standard & $\begin{array}{l}\text { Applied the } \\
\text { body size }\end{array}$ & $\begin{array}{c}\text { Guideline of } \\
\text { design dimension }\end{array}$ \\
\hline \multirow{4}{*}{$\begin{array}{l}\text { Seat } \\
\text { pan }\end{array}$} & Height & $\begin{array}{l}\text { Popliteal height, Sitting } \\
\cdot 5 \% \text { tile of womem }+ \\
\text { Redundancy } \\
\cdot \text { Redundancy: } 35 \mathrm{~mm} \\
\text { (Park, 2003) } \\
\text { - Redundancy: } 40 \mathrm{~mm} \\
\text { (Kwak et al., 1999) }\end{array}$ & $\begin{array}{l}\cdot \text { More than } 350 \mathrm{~mm} \\
\text { (The Voluntary Safety } \\
\text { Standard of Korea, 2006) } \\
\cdot 5 \% \text { tile of women } \\
\text { 95\%tile of men }+ \\
3 \mathrm{~cm}(\text { Redundancy) } \\
\text { (BIFMAG1-2002) }\end{array}$ & $\begin{array}{l}\text { Minimum size } \\
\cdot 5 \% \text { tile of women } \\
\cdot 316.5 \mathrm{~mm}\end{array}$ & $360 \mathrm{~mm}$ \\
\hline & \multirow{2}{*}{ Width } & $\begin{array}{l}\text { Hip breadth, Sitting } \\
\cdot 95 \% \text { tile of men }+ \text { Redundancy }\end{array}$ & $\begin{array}{l}\cdot \text { More than 330mm } \\
\text { (KS G 4101) }\end{array}$ & $\begin{array}{l}\text { Maximum size } \\
\cdot 95 \% \text { tile of women } \\
\cdot 370.5 \mathrm{~mm}\end{array}$ & $450 \mathrm{~mm}$ \\
\hline & & $\begin{array}{l}\cdot \text { Redundancy: } 70 \mathrm{~mm} \\
\text { (Kwak et al., 1999) } \\
\cdot 8 \sim 10 \mathrm{~cm}(\text { Park, 2003) }\end{array}$ & $\begin{array}{l}\cdot 95 \% \text { tile }+2.5 \mathrm{~cm} \\
\text { (Redundancy) } \\
\text { (BIFMAG1-2002) }\end{array}$ & & $450 \mathrm{~mm}$ \\
\hline & Depth & $\begin{array}{l}\text { Buttock to popliteal } \\
\text { length, Sitting } \\
\cdot 5 \% \text { tile of women - } \\
\text { Redundancy } \\
\text { (Kwak et al., 1999) }\end{array}$ & $\begin{array}{l}\cdot \text { Seat depth: Below } 480 \mathrm{~mm} \\
\cdot 5 \% \text { tilt of women } \\
\text { (BIFMA G1-2002) }\end{array}$ & $\begin{array}{l}\text { Minimum size } \\
\cdot 5 \% \text { tile of women } \\
\cdot 401.5 \mathrm{~mm}\end{array}$ & $380 \mathrm{~mm}$ \\
\hline \multirow[b]{3}{*}{$\begin{array}{l}\text { Arm } \\
\text { rest }\end{array}$} & Height & $\begin{array}{l}\text { Elbow rest height, Sitting } \\
\cdot 50 \% \text { tile } \\
\cdot \text { Redundancy: } 20 \sim 40 \mathrm{~mm} \\
\text { (Park, 2003) }\end{array}$ & $\begin{array}{l}\cdot \text { Height of Seat pan } \\
210 \sim 250 \mathrm{~mm}(\mathrm{KS})\end{array}$ & $\begin{array}{l}\text { Middle size } \\
\cdot 50 \% \text { tile } \\
\cdot 235.5 \mathrm{~mm}\end{array}$ & $220 \mathrm{~mm}$ \\
\hline & Width & $\cdot 40 \sim 70 \mathrm{~mm}($ Park, 2003) & & & $60 \mathrm{~mm}$ \\
\hline & $\begin{array}{l}\text { Length } \\
\text { between } \\
\text { Armrests }\end{array}$ & $\begin{array}{l}\text { Biacromial Breadth } \\
\cdot 95 \% \text { tile } \\
\text { - Redundancy: } 20 \mathrm{~mm} \\
-50 \% \text { tile } ~ \\
\quad 95 \% \text { tile }+100 \sim 120 \mathrm{~mm} \\
\text { (Redundancy), (Park, 2003) }\end{array}$ & $\begin{array}{l}\cdot \text { More than } 420 \mathrm{~mm}(\mathrm{KS}) \\
\cdot \text { Hip breadth, Sitting } \\
\cdot 95 \% \text { tile of women }+ \\
25 \mathrm{~mm}(\text { Redundancy) } \\
\text { (BIFMA G1-2002) }\end{array}$ & $\begin{array}{l}\text { Maximum size } \\
\text { Hip breadth, Sitting } \\
\cdot 95 \% \text { tile of women } \\
\cdot 370.5 \mathrm{~mm} \\
\text { Maximum size } \\
\text { Biacromial Breadth } \\
.95 \% \text { tile of men } \\
.552 \mathrm{~mm}\end{array}$ & $470 \mathrm{~mm}$ \\
\hline
\end{tabular}

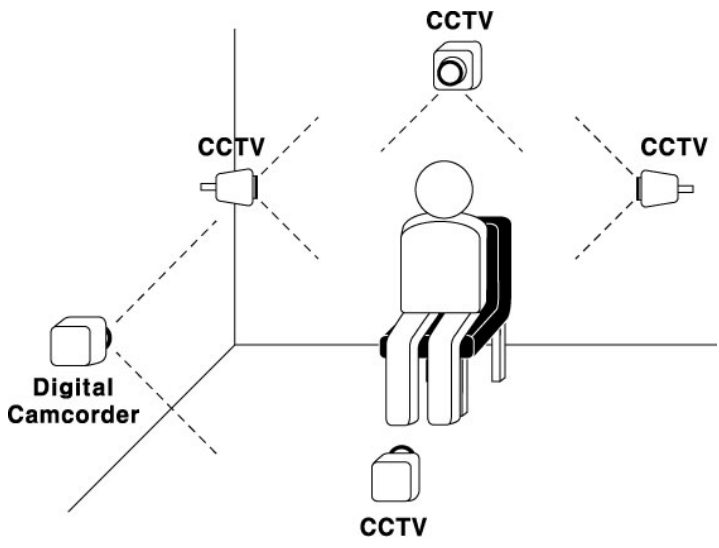

Figure 2. Observation system in the shower

\subsection{Method of scene analysis}

(Figure 3)에 제시한 신체구역에 따라 피실험자의 샤워 시 행동 패턴을 분석하였다. 피실험자의 신체부위를 14 곳으 로 구역화하여 구분하였고, 분석 시 14 곳의 분석지점을 손 으로 문지른 횟수를 기록하였다.

\subsection{Results of observation}

구역화된 신체부위에 좌, 우 각각의 손으로 문지른 평균 횟수와 표준편차를 (Figure 4)에 나타냈다. 신체 각 부위에 서 나타난 각 손의 문지르기 동작에 관한 손 사용빈도를 비 교했을 때, 오른손보다 왼손사용이 더 많았다(56\%). 상반신 
부위의 손 사용빈도는 총 $69.5 \%$ 로 나타났고, 하반신은 총 $30.5 \%$ 로 상반신이 많이 사용된 것으로 측정되었다.

상반신은 머리부위 $17 \%$, 가슴 $14.1 \%$, 어깨 $9.4 \%$, 배 $6.6 \%$, 등 $0.4 \%$, 허리 $5.1 \%$, 팔 $16.3 \%$ 이고, 하반신은 사타 구니 $8.1 \%$, 엉덩이 $6.2 \%$, 허벅지 $9.9 \%$, 종아리 $6.6 \%$ 의 비 율로 손을 사용한 것으로 나타났다.

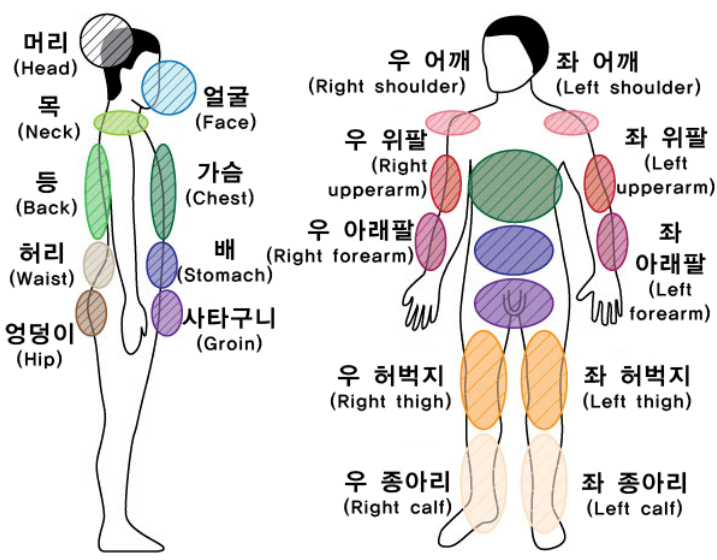

Figure 3. Labeling of body parts

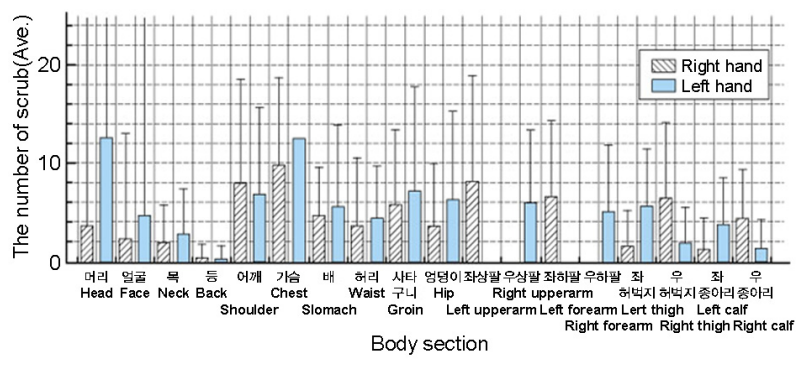

Figure 4. Cleaning frequency in shower

\subsection{Positioning nozzles by results of observation}

샤워 시 행동특성 결과를 반영하여 실험장치를 제작하였 다. 신체 앞부분의 상반신에 $40 \%$, 사타구니에 $20 \%$ 의 비중 으로 샤워노즐을 분포시켰으며, 신체 뒷부분의 상체(등, 허 리)/하체 $40 \%$, 엉덩이 부위에 각각 $20 \%$ 의 샤워노즐을 분 포시켰다. 이러한, 샤워노즐 분포에 따라 샤워 세정실험장치 를 설계/제작하였다.

\section{Optimizing Nozzle Position}

노즐위치 최적화는 먼저, 샤워 행동특성 분석결과를 적용
한 샤워 실험장치를 활용한 세정실험을 통하여 세정이 이뤄 지지 않는 부분의 노즐위치를 조정하였다. 현실적으로 실험 장치 상에서 구현이 어려운 노즐위치 구현을 위해 샤워 세 정 시뮬레이션 기법을 통하여 구현하였고, 컴퓨터 설계데이 터를 얻어 최종 제품설계에 적용할 수 있는 최적화된 노즐 위치 데이터를 도출하였다(Kim et al., 2008).

\subsection{Prototype for washing test}

세정실험을 위한 실험장치는 샤워 시 고령자의 행동특성 의 결과를 바탕으로 제작되었다. 또한 노즐의 개수, 위치, 분사각을 조절할 수 있도록 설계하였다. 이와 같은 실험장치 를 통한 세정실험에서는 노즐의 개수 및 위치, 분사각을 변 화시켜가며 세정실험을 수행하였다(Figure 5).

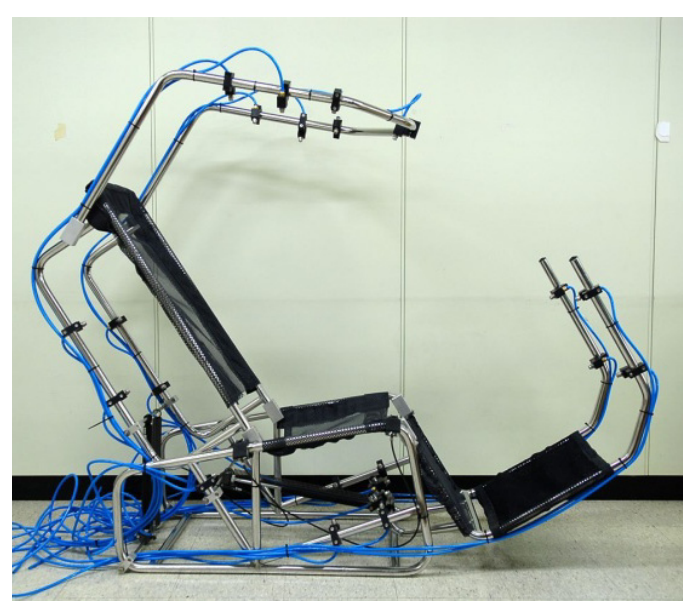

Figure 5. Experiment equipment for washing test

\subsection{Method of washing test}

노즐위치에 따른 세정범위를 파악하기 위하여 샤워 세정 실험을 실시하였다. 세정실험은 마네킹의 전면부에만 페인팅 을 하였고, 5 분 간 자연건조 후 실험을 수행하였다(Figure 6). 10 초 후, 20 초 후 두 번 실험결과를 촬영하였고, 실험 후 사진에서 페인팅이 남아있는 부분을 이미지화하여 결과 를 정리하였다. 이러한 실험결과를 바탕으로 노즐의 위치를 재조정한 후 반복하여 실험을 실시하였다.

\subsection{Results of washing test}

마네킹 표면에 바디 페인팅을 한 후 실시한 세정 실험결과 는 (Figure 7) 과 같이 이미지화하여 분석하였다. 주된 실험 결과를 살펴보면 10 초 간 분사한 후의 결과는 허벅지 부분 
과 목 어깨 부분이 세정되지 않은 것으로 드러났고, 20초 간 분사한 후 촬영한 실험결과에서는 10 초 후에서와 같이 여전 히 허벅지 부분이 세정되지 않은 것으로 나타났다.

실험결과에 나타난 세정되는 않은 부분들은 실험장치상에 서는 구현할 수 없는 노즐의 위치들이 존재하기 때문이다. 허벅지 부분에 물을 분사할 수 있는 노즐을 위치시키기 위 해서는 실험장치를 다시 제작해야 한다. 따라서 이러한 실험 장치상의 한계를 극복하고 최적화된 노즐위치를 구현하기 위해서 노즐의 분사형태를 형상화하여 샤워 시뮬레이션을 통한 노즐위치 최적화 과정이 필요함을 알 수 있었다.

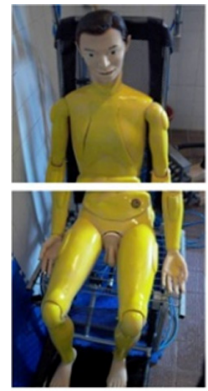

Before washout

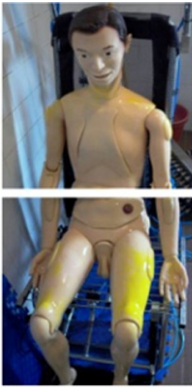

After 10 seconds

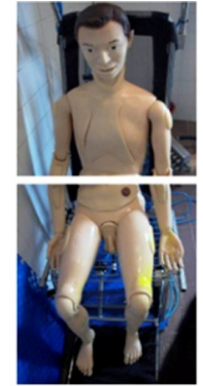

After 20 seconds
Figure 6. Showering test on body painting

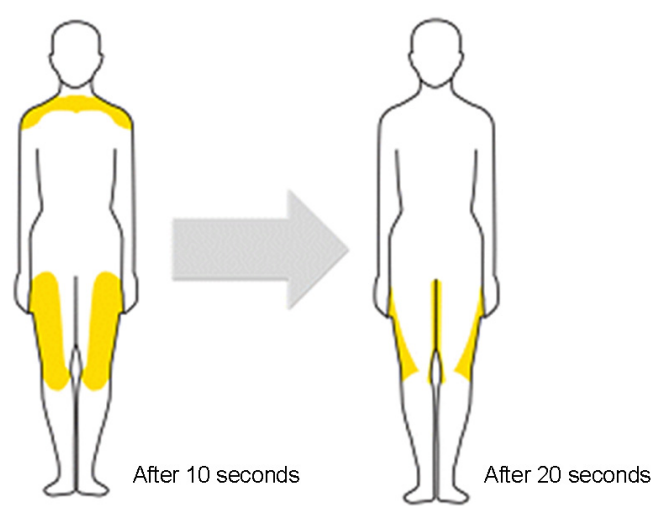

Figure 7. Results of showering test by image

\subsection{Method of showering simulation}

샤워 세정 시뮬레이션을 위해서는 노즐 분사형태의 형상 화가 필요하기 때문에 형상화에 필요한 치수정보를 얻기 위 한 노즐 분사 거리 별 세정범위를 측정하였다.

아크릴 판에 페인팅을 한 후, 실험장치에 쓰이는 노즐 한 개를 분사하였다. 아크릴판과 노즐의 거리를 $100 \mathrm{~mm}, 200$ $\mathrm{mm}, 300 \mathrm{~mm}, 400 \mathrm{~mm}, 500 \mathrm{~mm}$ 로 하여 물을 분사한 후 세 정범위의 직경을 측정하여 결과를 정리하였다(Figure 8).

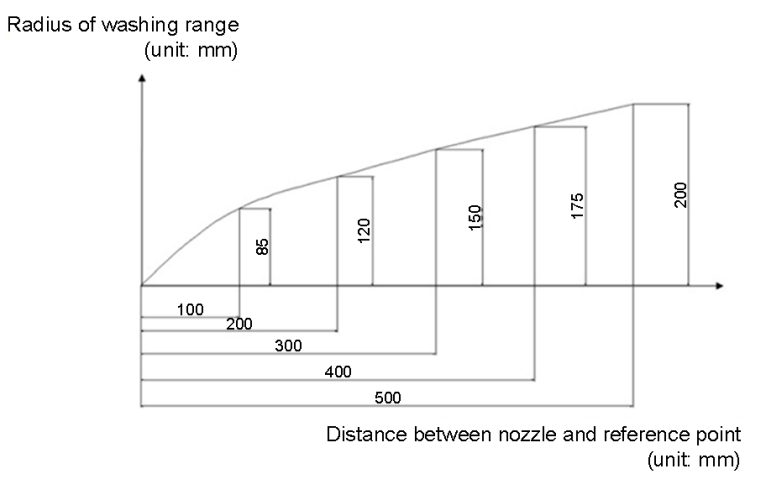

Figure 8. The nozzle cleaning range by distance

거리 별 세정범위결과를 통해 노즐 분사형태를 형상화하 였으며 이를 통해 노즐위치 최적화를 위한 샤워 세정 시뮬 레이션을 실시하였다.

\subsection{Results of showering simulation}

노즐위치와 분사각도로 인해 전혀 물이 닿지 않는 허벅지 부분, 노즐과 몸 간의 거리가 너무 멀어 노즐간의 거리가 $300 \mathrm{~mm}$ 를 벗어난 몸통 부분, 그리고 노즐과의 거리가 너무 가까워서 분사면적이 너무 좁아 세정되지 않는 종아리 뒷부 분은 (Figure 9)의 오른쪽 그림과 같이 노즐위치나 각도를 조정하였다.

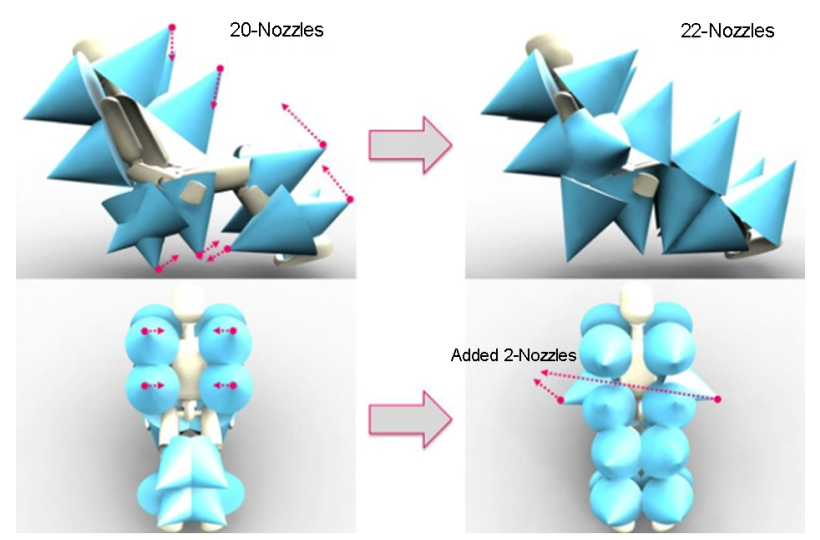

Figure 9. Optimizing nozzle position, degree by simulation

또한 상대적으로 피부에 수직으로 분사되는 노즐이 없어, 세정에 취약한 옆구리 부분과 겨드랑이 부분을 보완하기 위한 두 개의 노즐을 양쪽에 각 1 개씩 추가 하였다. 


\section{Design of Automatic Shower Chair for Elderly}

고령자가 사용하는 자동샤워시스템 디자인에 있어서는 우 선적으로 앞의 연구결과인 최적화된 노즐위치를 반영하여 전체적인 형태의 디자인과 구조설계를 실시하였다.

기존 자동샤워시스템들은 시설과 요양병원을 대상으로 개 발되어 제품의 부피가 너무 큰 단점이 있었다. 이러한 부피 상의 문제는 가정에 사용하기에는 불가능하였고, 이러한 부 피상의 문제점을 해결하기 위해 제품을 모듈화하여 조립식 으로 디자인하여 협소한 공간에서도 용이하게 설치할 수 있 게 하였다.

또한 기존 샤워시스템들이 노즐의 세기나 개수로 인해 많 은 물을 사용하는 문제점을 줄이기 위하여 적은 노즐로 많은 범위를 세정할 수 있는 스윙노즐을 디자인에 적용하였다.

\subsection{Nozzle position and design}

노즐은 몸을 세정할 수 있는 총 22개의 노즐과 머리를 감 을 수 있는 노즐 1 개 총 23 개의 노즐로 이루어져 있다.

그 중에 4 개의 노즐은 스윙노즐로 이루어져 몸의 앞쪽 부 분과 허벅지 부분에 물을 분사하게 이루어져 있다. 이와 같 이 최적화된 노즐들을 우선 배치하여 노즐위치 중심으로 프 레임을 구성하고, 내부 구조설계를 실행하였다(Figure 10).

외부 디자인 역시 최적화된 노즐위치와 스윙노즐의 분사 범위와 앞서 조사한 인체치수에 근거한 디자인 가이드라인 을 참고하여 최종적인 디자인을 실시하였다.

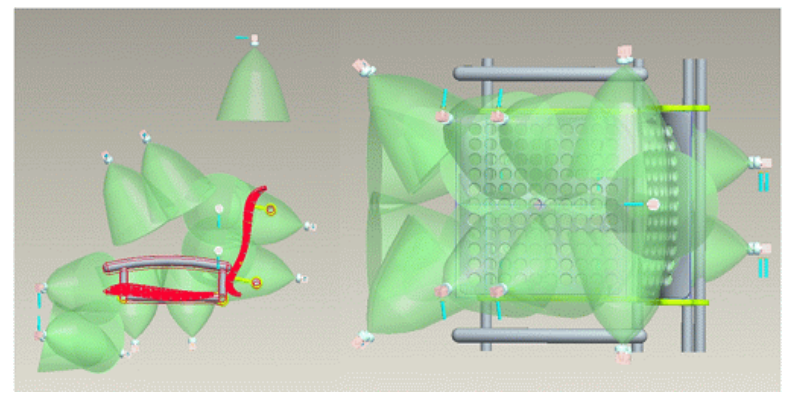

Figure 10. Design by nozzle position

\subsection{Case design of prefab structure}

자동샤워시스템의 조립구조는 좌 · 우측 프레임과 가운데 몸체 프레임으로 조립된다. 조립구조의 디자인은 가정집의 욕실 문 사이즈가 $900 \mathrm{~mm}$ 정도임을 고려하여 이러한 문을
통과하여 일반가정의 욕실 내 설치가 가능하게 하기 위한 디 자인이다. 이와 같은 조립구조가 가능하게 하기 위하여 좌우 측 프레임에 연결된 노즐의 배관을 유연한 배관을 사용하여 설계하였다.

\subsection{Using of swing nozzle}

스윙노즐은 자동샤워시스템에 크게 두 가지의 긍정적인 효과를 가져오는 디자인 요소이다.

첫 번째로 스윙노즐은 적은 수의 노즐로 넓은 범위를 세정 할 수 있어 노즐의 숫자를 줄이고, 한 개의 노즐당 2 분 샤워 시 5 10리터 정도의 물을 절약할 수 있는 장점을 가지고 있다.

두 번째 장점은 몸 앞쪽의 노즐 수를 줄임으로써 샤워의자 의 출입구 역할을 하는 통로 공간을 확보할 수 있었다. 이러 한 두 가지 장점을 가지고 있는 스윙노즐을 최종 시제품 디 자인에 반영하였다.

\subsection{Prototype design}

좌식형 자동샤워시스템의 최종 시제품 디자인은 (Figure 11) 과 같다. 본 제품의 개발은 노즐위치와 분사각을 최적화 하는 것을 기준으로 최적화 결과를 설계와 디자인에 반영하 였다. 앞선 연구 내용(실험, 시뮬레이션)의 프로세스에 따라 최종적인 디자인을 수행하였다. 시제품의 색상은 고령자에게 편안한 느낌을 줄 수 있는 파스텔계열의 색상을 사용하였다. 또한 고령자의 안전사고를 방지하기 위하여 모서리 부분은 모두 둥글게 처리하여 디자인 하였다(Fisk et al., 2009).

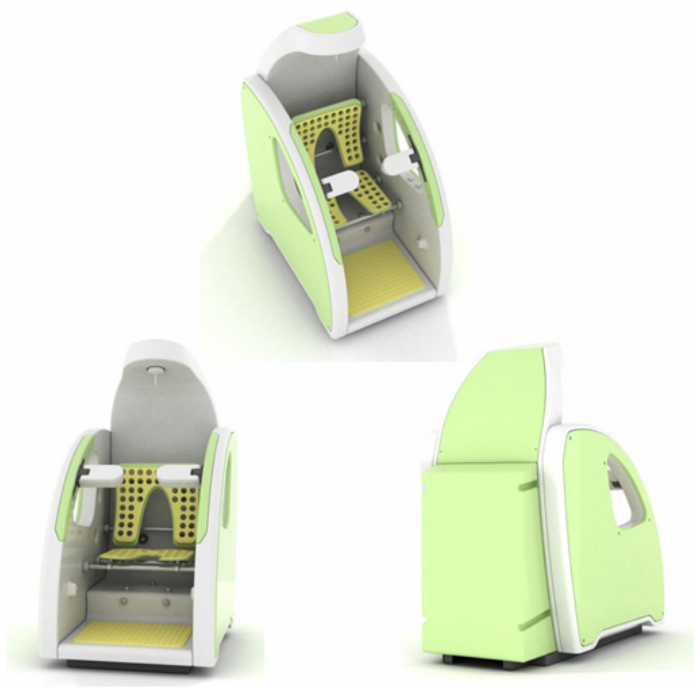

Figure 11. Prototype design of automatic showering system 


\section{Conclusion}

본 연구는 몸이 불편한 고령자를 위하여 일상생활 중에서 가장 기본적인 생활의 하나인 샤워를 수발할 수 있는 자동샤 워시스템을 개발하는 것을 목적으로 수행되었다.

고령자의 인체치수 적용, 고령자의 행동특성 분석, 세정실 험과 샤워 세정 시뮬레이션을 통한 노즐위치의 최적화 과정 을 거쳐 디자인을 수행하였다. 또한 가정의 욕실 문을 통과 하기 위한 조립식 구조와 물을 절약하기 위한 스윙노즐을 적용하여 최종적인 디자인을 수행하였다.

본 논문은 제품개발 사례연구이고 노즐위치 및 분사각 최 적화라는 핵심목적을 중심으로 이루어져 있는데, 이는 노즐 위치 및 분사각의 최적화가 자동샤워시스템의 개발이 있어 가장 중요한 디자인요소이기 때문이다. 손을 쓰기 불편한 고령자의 샤워에서 물이 몸 전체에 고르게 분사될 수 있게 하는 것이 노즐위치 및 분사각 최적화 기술이라고 판단했기 때문이다.

본 논문에서처럼 제품을 개발할 때 사용자에게 가장 중요 한 디자인요소를 도출하고, 디자인요소를 정량화하여 제품개 발(디자인)에 반영하는 과정은 사용자 중심적인 제품개발할 수 있는 좋은 방법들 중에 하나이다. 이러한 제품개발 사례 연구는 앞으로 사용자의 중심적인 제품개발과 더불어 사용 자에 대한 고려가 중요한 복지기기(장애인 기기), 고령친화 제품의 개발에 널리 활용될 수 있을 것으로 기대된다.

\section{References}

Chun, K. J., et al. Development of An Intelligent Care-free Bathing/ Showering System for Elders, Report, Ministry of Knowledge Economy, 2009.

Chun, K. J., Park, K. R., Jung, W. W. and Rhee, K. H., A Study of Behavioral Characteristic of Elders during Showering, Korean Society for Precision Engineering, 24(7), 2007.
Fisk, A. D. and Rogers. W. A., Designing for Older Adults(second edition), Taylor \& Francis Group. 2009.

Kim, J. H., Hong, J. S. and Chun, K. J., A Study of Optimizing the Nozzle Position based on Behavioral Characteristic of Elder during shower, The 2008 conference of Korean Society for Precision Engineering, 2008.

Kwak, W. M., Hong, S. S., Jung, S. G., Lee, S. D., Lee, D. C. and Yoon, H. Y., Ergonomics Design of office Chair., Korea society of Design Science, 31, 73-80, 1999

Park, S. C., An Ergonomic Study on the Design and Evaluation for Office Chair, Graduate School Chungnam National University, 2003.

Size Korea, http://sizekorea.kats.go.kr.

\section{Author listings}

\section{Jonghyun Kim: ddalki@kitech.re.kr}

Highest degree: MS, Department of Industrial Design Engineering, KUT Position title: Researcher, Gerontechnology Center, KITECH Areas of interest: User Analysis, Usability test

Jaesoo Hong: jshong94@kitech.re.kr

Highest degree: MS, Department of Mechatronics Engineering, KUT Position title: Researcher, Gerontechnology Center, KITECH Areas of interest: User Analysis, Usability test

Keyoungjin Chun: chun $@$ kitech.re.kr

Highest degree: Ph. D, Department of Biomechanics, Michigan State Univ.

Position title: Senior Researcher, Gerontechnology Center, KITECH Areas of interest: Development of senior friendly product

Date Received : 2010-12-06

Date Revised : 2011-09-16

Date Accepted : 2011-09-21 